\title{
DESENVOLVIMENTO, PÓS-ESTRUTURALISMO E PÓS-DESENVOLVIMENTO \\ A crítica da modernidade e a emergência de "modernidades" alternativas
}

\section{Guilherme Francisco Waterloo Radomsky}

Com uma história de mais de meio século de políticas, programas, debates acadêmicos e teóricos acalorados, o tema do desenvolvimento perpetua-se insistentemente nas ciências sociais. A "década perdida" e a efetivação de princípios de governo neoliberais pareciam prometer soterrar um tópico que

* Este artigo é um dos resultados do estágio como Research Scholar na University of North Carolina at Chapel Hill (2009-2010). Sou grato a Arturo Escobar por proporcionar-me condiçóes de trabalho e estudo e a Walter Mignolo pela oportunidade de participar do seminário "Education, Development, Freedom" na Duke University. As discussões com Ondina Leal, Javier Pabón, Adriana Paredes e Rodrigo Medeiros enriqueceram o texto. Agradeço também às contribuições dos pareceristas anônimos da $R B C S$ e ao CNPq pela concessão dos recursos financeiros. Todas as incoerências e incorreções deste artigo são responsabilidade do autor. se consolidou a partir da centralidade do Estado na condução das economias e de programas de desenvolvimento integrados e se nutriu da oposição, passível de ser vencida (pelo menos como princípio de esperança), entre países desenvolvidos e subdesenvolvidos desde o famoso discurso de Harry Truman em 1949.

No entanto, com todas as vicissitudes e os desgastes, a ideia de desenvolvimento (e todos os derivados que geralmente aparecem ligados ao termo "desenvolvido": sub, semi, pós) não perde força imaginativa e poder conceitual, mesmo em meio à ruína que um olhar crítico poderia depurar. Artifício ideológico, implicação de um poder discursivo ou esperança de superação de problemas como a pobreza e a desigualdade, deve-se destacar sua resiliência diante das tentativas de desconstrução. Mesmo assim, parece ter se tornado chave a suspeita de que a discussão sobre o desenvolvimento nas ciências sociais e no campo das políticas pú- 
blicas (com a intervenção de agências e entidades nacionais e internacionais) resiste não por colocar em pauta um assunto inquestionável, um bem comum cuja finalidade seria indubitável; tampouco sustenta-se por ser um recurso de poder que subjaz nas "entrelinhas" do processo e que se esconde na medida em que é um artifício para manutenção de status quo. Ambas são verdades (parciais, talvez) e, portanto, a elas escapam desejos e seduçóes que o "campo do desenvolvimento" (Ribeiro, 2005) produz e alimenta para seu funcionamento.

Novos enfoques procuram recuperar a energia perdida do campo, após testemunharem a falácia de programas de investigação e de receituários que tiveram êxito temporário nos anos de 1960 e 1970, amparando-se nas noções de modernização social e crescimento econômico. Rompendo com velhos paradigmas, a ânsia do desenvolvimento desenha agora caminhos plurais e heterogêneos com diferentes matizes. No Brasil, é quase lugar comum entre especialistas a obra de Amartya Sen, que quase adquire um véu aurático e de ponto de mutação sobre o tema renovando a esperança redentora do desenvolvimento - agora "como liberdade". Além deste, são especialmente incorporados ao debate a perspectiva sobre capital social, a crítica do desenvolvimento igualado a crescimento (propagado pela noção de desenvolvimento sustentável) e os novos olhares sobre as instituiçôes como centrais para a mudança social.

Como tal, o Estado não tem mais o protagonismo; no entanto ele não desaparece do cenário, tal qual a proposta novo-desenvolvimentista com matizes que ora enfatizam sua maior participação, ora evocam a importância do mercado (global) para consecução de objetivos nacionais primordiais (Bresser-Pereira, 2006). Noutro ponto, sem descartar que a presença estatal é matricial, fórmulas de articulação descentralizada avaliam positivamente a emergência de atores sociais locais, tornando relevantes os processos territoriais de desenvolvimento (Abramovay, 2003; Schneider, 2004).

Comum a este debate é a arquitetura que reveste de tempos em tempos o desenvolvimento com novos adjetivos e que se propõe a revitalizar sua importância, tanto na academia como nas relaçôes entre organizaçôes da sociedade e o Estado.
Menos discutidos pela ciência social brasileira, entretanto, são os pontos de vista elaborados pela antropologia do desenvolvimento e pelas perspectivas pós-estruturalista e pós-colonial sobre o assunto, quando nos anos de 1990, o diálogo crítico permitiu o aparecimento da perspectiva denominada de pós-desenvolvimento. Enquanto a primeira, durante longo tempo, dedicou-se a facilitar ou auxiliar as transformações desejadas pelos developers (ainda que se complexificou com o tempo e seus porta-vozes têm repensado esse papel), as perspectivas pós-estruturalista e pós-colonial nascem com objetivo inverso. É verdade que o pós-estruturalismo e o debate pós-colonial já faz parte do manancial teórico das ciências sociais no Brasil desde longa data, no entanto uma parte colossal dessa literatura em âmbito internacional se dedica ao escrutínio crítico do desenvolvimento e tem encontrado menores ressonâncias em nossas fronteiras.

Neste texto, examino parte da trajetória que inicia com a crença primordial na eficácia das transformaçôes sociais planejadas - concedendo particular espaço aos escritos antropológicos sobre o assunto, mas não restrito a eles - e encontra ponto de tensão na crítica do desenvolvimento como narrativa e prática de poder. $\mathrm{O}$ ponto fundamental será mostrar os argumentos principais que confluem para a perspectiva (bastante diversa, é verdade) do pós-desenvolvimento e, consequentemente, críticas posteriores que este recebeu por parte dos defensores do desenvolvimento. Este panorama culmina em recuperar a defesa impetrada pelos autores ligados ao pós-desenvolvimento e, desse modo, avançar para dois argumentos contraditórios e relacionados. De um lado, a desconstrução do desenvolvimento adquire força ao descentrar o viés eurocêntrico sob o qual está erigida a teoria social, o que introduz uma geopolítica da epistemologia e uma virada político-interpretativa para as contribuições que se orientam pela noção geral de descolonização. De outro, como a contra-crítica ao pós-desenvolvimento sugere, ao problematizar o lugar da enunciação e ao interpretar o desenvolvimento como uma máquina, a perspectiva parece não encontrar ecos no mesmo momento que nega a sedução das narrativas, a agência efetiva dos que vivem as políticas e os programas, e os desejos articulados a ambos. 


\section{Antropologia, desenvolvimento e pós-estruturalismo}

Enquanto o final da década de 1960 testemunhava uma rediscussão do problema da modernização na sociologia e na ciência política, outros dilemas cercavam o campo da antropologia. Alguns autores atribuem as origens de "uma possível" antropologia do desenvolvimento (Schröder, 1997) aos projetos coloniais e ao ramo da antropologia aplicada, sempre muito contestada em países como os Estados Unidos e já em atividade desde os anos de 1930 (Gardner e Lewis, 1996). Um das questôes cruciais era o caráter ainda colonial da própria disciplina que estaria a serviço dos governos imperiais (ou das ex-colônias), cuja eficiência era dada pelo sucesso como tipo de conhecimento específico para resoluções de problemas culturais locais (tribais ou com camponeses). Desse sucesso dependia o auxílio de agências internacionais que financiavam projetos. A valorização recaía no trabalho de "lubrificação", em que antropólogos atuavam como brokers para verificação in loco das possibilidades de auxílio externo, sempre persuasiva para elites locais, bem como no acompanhamento dos projetos implantados.

Trabalho amplamente conhecido na literatura sobre antropologia e desenvolvimento, a publicação de Cochrane (1971) é o ápice de uma ideologia pró-desenvolvimento em que a prescrição é entendida não apenas salutar, mas indispensável. Diferente do debate entre economistas e sociólogos que se debruçavam sobre problemas de estrutura agrária, classes operárias e modelos de distribuição de riqueza - , a antropologia precisava enfrentar uma suposta alteridade radical, na medida em que o "outro" vinha a ser o alvo da política de transformação. Pela importância na época, chama a atenção que o trabalho de Cochrane pouco discuta o que é desenvolvimento, ou seja, ele o toma como dado e de uma forma descritiva em que processos de transformação comportamental são elementares. A mudança não seria senão induzida externamente e com base nos moldes elaborados por agências de desenvolvimento, cujos modelos de modernização eram amparados em aspectos como aumento da produção, eficiência econômica, crescimento da produtividade de setores agrícolas e racionalidade no uso dos fatores. $\mathrm{O}$ autor, ao final, numa formulação que pareceria nefasta hoje até mesmo para os eloquentes defensores da ajuda externa, pontua que os antropólogos precisam entender as necessidades dos governos e das agências (e nada declara a respeito das populações que sofrem mudanças).

Nas nações ditas desenvolvidas, este era um clima em que posicionava antropólogos em meio à discussão sobre seu papel a favor de mudanças sociais, sem uma atenção maior sobre quais mudanças e se elas seriam benéficas. Parte dos anos de 1980 foi marcada por essa perspectiva, que lentamente era minada por dentro e por fora (Grillo, 1985). ${ }^{1}$ Informar o debate, formar opinião pública, interpretar as culturas para outsiders e auxiliar formuladores de políticas bastavam como horizonte possível em prol do desenvolvimento conduzido por Estados com ajuda internacional, respeitando a máxima do ex-presidente dos Estados Unidos, Harry Truman, de que os países desenvolvidos deveriam "ajudar os outros [países] a se ajudarem" (Rist, 2008, p. 134).

Outra questão que marcou a antropologia aplicada das décadas de 1970 e 1970 foi a existência de povos tradicionais no interior dos territórios de naçôes consideradas desenvolvidas, ou mesmo nas periféricas, em que setores modernos também apareciam. Nesse último caso, em que Brasil, Peru, México e outros países latino-americanos são exemplos, o debate obedeceu aos critérios de tentativa de uma interpretação nacional em que a antropologia participava com as outras ciências sociais. No Brasil, a dicotomia entre setores "atrasados" e "modernos", cujo conflito interpretativo procurava entender o lugar e a relação entre ambos (na famosa polêmica entre Ignácio Rangel e Francisco de Oliveira), encontrava eco nas análises de povos indígenas pouco integrados à sociedade nacional. Nesse hiato, emerge uma antropologia preocupada com o desenvolvimento sem perder de vista o caráter particularista, especialmente em nações em que serviços de proteção ao índio existiam. Neste caso, é sintomático que a noção de etnodesenvolvimento, entendida como dimensão esquecida durante muito tempo, demarque um repensar do desenvolvimento quando pluralidade cultural é antes um desafio do que um problema. ${ }^{2}$ 
Este clima propiciou reflexões diversas. Minha impressão é de que a discussão no âmbito da antropologia (com a sua contestação interna e externa como "disciplina do saber colonial", conforme Asad, 1973) favoreceu o aparecimento de proposiçôes críticas radicais ao desenvolvimento. Nela, comparada às outras ciências sociais, a interpretação privilegiou o desenvolvimento enquanto equacionado a representações, prescriçōes, mensagens e significados (Hobart, 1993; Corbridge, 1994). No entanto, é preciso relativizar esta afirmação. As condiçôes para tal processo tiveram efeito real na recepção de Foucault, na emergência do pós-colonialismo (sendo central o trabalho de Said (1978) sobre o orientalismo) e na desconstrução pós-moderna. Nesse sentido, foi essencial para a antropologia uma atmosfera favorável para absorção desses prismas, mas não se pode afirmar que a antropologia orientada pró-desenvolvimento tenha perdido seu espaço; ao contrário, o número de profissionais em cargos do Banco Mundial e agências aumenta. Por outro lado, autores como Gustavo Esteva e Gilbert Rist, mais vinculados às ciências econômicas e aos development studies, e igualmente Vandana Shiva e Majid Rahnema forneceram outras ligações importantes para o questionamento dos modelos de desenvolvimento planejado. Paralelamente, uma quantidade de trabalhos de grande fecundidade apareceu na chance de uma reciclagem do tema para que se enfrentassem desafios não resolvidos pelas políticas anteriores e ofuscados por teorias obtusas.

Pode-se mencionar, entretanto, que o problema ambiental exerceu um efeito espetacular ao tentar impedir novas possibilidades de se reinventar o tópico. Embora mais significativo em intelectuais isolados ou movimentos sociais, é preciso pontuar que mesmo nos setores acadêmicos essa perspectiva teve efeitos, inclusive nas propostas de crescimento zero, slow down consumption e outras (Veiga, 2006). Em todo o caso, excetuando-se as propostas mais agressivas em prol da recuperação de áreas degradadas e da defesa fervorosa da natureza (supostamente) intocada, o que de fato perdurou como tema acadêmico desde a Conferência das Nações Unidas sobre o Meio-ambiente $\mathrm{Hu}$ mano em 1972 - e o famoso relatório do Clube de Roma intitulado Limites do Crescimento - foi a construção de uma alternativa em torno de um lema: o desenvolvimento sustentável. ${ }^{3}$

Em meados dos anos de 1980, a crítica ao desenvolvimento começa a se tornar mais forte no interior da antropologia. Dahl e Hjort (1984) apresentam o problema de a "development anthropology" ter focado insistentemente na organização técnica da ajuda internacional (como se a própria discussão do que é desenvolvimento fosse secundária) e aparece a ideia de uma ideologia do desenvolvimento na sua mensagem e sua exportação. No entanto, é entre 1985 e 1987 que emergem dois trabalhos cujos ímpetos se direcionam claramente à desconstrução do desenvolvimento. Resultados de duas teses de doutorado e transformadas em livros alguns anos depois, Ferguson (1990) e Escobar (1995) não procuram um balanço reflexivo que permita a refundação dos seus resíduos positivos, mas a implosão da sua narrativa subjacente. Cabe ressaltar: ambos os autores valem-se da perspectiva de Michel Foucault sobre governamentalidade e se concentram na armadura que formou o dispositivo do desenvolvimento.

Detenho-me nestes dois autores por um momento. Ferguson (1990) toma como objeto a análise de um grandioso projeto de desenvolvimento rural no Lesoto e se volta para o dispositivo que permitiu sua operação. Em termos teóricos, duas visões disputavam hegemonia, até então: a modernização e o neomarxismo dependentista. Na primeira, o dispositivo de desenvolvimento é positivo e essencial para o planejador poder "melhorar" a situação-alvo; na segunda, de caráter crítico, mostram-se as lacunas e aquilo que o desenvolvimento deixa de fazer. Por sua vez, Ferguson empenha-se a mostrar, com fracassos e sucessos (totais ou parciais), o que o desenvolvimento faz. Em última instância, ele funciona como uma máquina antipolítica:

[...] resultados que, a princípio, parecem como meros "efeitos colaterais" de uma tentativa malsucedida para engendrar uma transformação econômica tornam legíveis outras perspectivas como não intencionadas, ainda que instrumentais, elementos em uma constelação 
resultante que tem o efeito de expandir o exercício de um tipo particular de poder do Estado enquanto simultaneamente exerce um efeito despolitizante poderoso. E esta constelação resultante "sem autor" eu chamo de máquina antipolítica [...] (Ferguson, 1990, pp. 20-21). ${ }^{4}$

A máquina antipolítica age de modo acrítico. Para poder implementar projetos de desenvolvimento num espaço qualquer, o aparelho estatal, os organismos e as agências multilaterais precisam "acomodar-se" aos problemas de desigualdade social e conflitos locais, no mais das vezes sem tocá-los; caso contrário, não haverá alianças locais a fim de torná-los praticáveis. Ademais, o que se processa em organismos e agências propositoras de projetos é tributário de um diagnóstico que olha a realidade social a partir da ideia de "falta", de algo a ser corrigido ou imputado e que o desenvolvimento, na forma de programa integrado com racionalidade própria, será o responsável pela efetuação.

Esta última dimensão é mais enfaticamente escrutinada por Arturo Escobar. No seu Encoutering development, o autor faz um estudo sistemático e global sobre a "era do desenvolvimento": sua invenção, a infantilização do "terceiro mundo" e o esquema de poder em cascata que partia de uma preocupação/interesse dos países desenvolvidos, passava por agências e organismos internacionais e chegava à importação e implementação por Estados "subdesenvolvidos" e seus níveis de ação regionais e locais. Embora o livro examine planos de desenvolvimento levados a cabo na Colômbia, sua vasta pesquisa bibliográfica e a articulação do caso colombiano com programas do Banco Mundial mostram que o problema atingiu países da Ásia à América passando pelas ilhas do pacífico e pelo continente africano.

Escobar sustenta que o desenvolvimento, mesmo falhando, produz coisas, ideários, disciplinas; a isso ele denomina de efeito de instrumento. Formas de conhecimento local e modelos de compreensão da natureza são sacrificados em favor de um modo racional de governo com a constituição de programas de alavancagem econômica, supostamente geradores de bem-estar a populações entendidas como pobres. Portanto, para Escobar não há espa- ços para reparação do desenvolvimento, a necessidade é uma superação do modelo como um todo:

O desenvolvimento foi - e continua a ser em grande parte - uma abordagem de cima para baixo, etnocêntrica e tecnocrática que trata as pessoas e culturas como conceitos abstratos, estatísticas que podem ser movimentadas para cima e a para baixo em gráficos de progresso (Escobar, 1995, p. 44).

O ponto de vista de Escobar salienta que a violência não é um efeito do descaso, do acesso desigual a políticas e dos efeitos prometidos e não cumpridos dos programas. Ele é o resultado próprio do dispositivo como um todo, ao movimentar, planejar, quantificar a vida das pessoas. Para tal efeito se cumprir, a visualização é basilar, fato característico da modernidade; assim o regime objetificador é a luz necessária para o dispositivo verificar e controlar (Idem, p. 155). Essa economia só faz sentido quando a máquina é tão poderosa e o desenvolvimento, menos que um conjunto discursivo e prático suplementar ao panorama moderno, transfigura-se num modo de entendimento da modernidade ocidental a respeito do mundo, uma espécie de lente pela qual a realidade é observada, medida e escalonada (Escobar, 1995, 2000); ou, na versão mais recente de Ferguson (1999), um mito que organiza a interpretação das pessoas sobre a história (linear e progressiva).

De modo que entre as publicaçôes de Ferguson (1990) e Escobar (1995) (cujos primeiros trabalhos aparecem ainda nos anos de 1980), e no período subsequente, um fluxo de artigos e livros orientados pelo pós-estruturalismo, pelo debate pós-moderno e pela perspectiva pós-colonial torna-se vigoroso em direção a um momento histórico, desejado por seus autores, que possa estar livre dos incômodos do desenvolvimento. Os mais conhecidos são a coletânea organizada por Sachs (1992), os trabalhos de Gustavo Esteva (1992), a edição organizada por Rahnema e Bawtree (1997) e o primoroso livro de Rist (2008). O ápice deste debate é o que fornece o título da conclusão do livro de Escobar - noção que também se tornou ponto de encontro entre muitos desses autores antes mencionados - e se sin- 
tetiza na possibilidade de "imaginar uma era pós-desenvolvimento".

\section{Pós-desenvolvimento: noções, respostas e réplicas}

O pós-desenvolvimento dificilmente poderia ser considerado um programa unitário e homogêneo de pensamento. Como movimento intelectual, o que aproxima autores é a crítica (variada) do modelo de desenvolvimento planejado que efetivou transformaçôes sociais radicais desde meados do século XX. Mais que um projeto comum, conexões parciais aparecem entre os propositores e, por razôes de espaço, concentro-me, nesta parte, em apenas duas contribuiçôes que penso serem básicas para o entendimento da proposta, a de Gilbert Rist e a de Arturo Escobar. ${ }^{5}$ Com isso, será possível privilegiar as respostas contrárias ao pós-desenvolvimento e as réplicas.

A sutileza da análise de Rist suaviza o arcabouço "excessivamente foucaultiano" em direção a uma crítica histórica que mostra, fracasso após fracasso, a ruína do desenvolvimento nas iniciativas e expressões de seus próprios porta-vozes. Contudo, o que é desenvolvimento, afinal? Esquivei de qualquer definição até o momento propositadamente para recuperar o que Rist considera como ponto de partida no entendimento:

"Desenvolvimento" consiste de um conjunto de práticas, às vezes aparecendo em conflito uma com outra, que requer - para a reprodução da sociedade - a transformação geral e a destruição do ambiente natural e das relações sociais. Seu objetivo é aumentar a produção de mercadorias (bens e serviços) direcionadas, pelo mecanismo da troca, para demanda efetiva (Rist, 2008, p. 13).

Esta definição é fundamental para o autor mostrar que o desenvolvimento, funcionando ancorado no mito do progresso e na concepção linear de história para o pensamento ocidental, se constitui como a "crença numa série de práticas que formam uma unidade apesar das contradições entre elas"
(Idem, p. 24). O ponto de partida do autor não possui, ao final, uma superação conceitual em direção a uma apreensão mais elaborada; ao desenvolvimento é preferível dizer adeus, não ressucitá-lo.

Rist mostra que a série de práticas em torno do desenvolvimento foi ganhando, ao longo das décadas, reformulações e críticas internas que, pouco a pouco, se tornaram o próprio reconhecimento do insucesso das teorias, dos programas e das políticas. A conferência de Bandung, os esforços de modernização, a crítica marxista e cepalina e as visões de multidimensionalidade do desenvolvimento (IDH formulado no âmbito do PNUD); o modelo da "autoconfiança" advogado por líderes de países do Sul Global, a ideia da necessidade de um "outro desenvolvimento", a conversão para formas sustentáveis e a abordagem das necessidades básicas; a South Comission, as metas do milênio e a perda da eficácia do discurso do desenvolvimento para um foco na redução da pobreza, todos apenas comprovam que o insucesso é parte deste motor. Programa após programa, reformulação e replanejamento, o discurso do desenvolvimento não se movimenta, ele apenas troca de figurino para obter nova energia que logo fracassa novamente. Portanto, diferentemente de Escobar, a análise histórica de Rist conclui com o "paradigma do desenvolvimento" tropeçando nos seus próprios pés.

Já Escobar parte de concepção ligeiramente distinta. Nos trabalhos recentes, embora não se afaste totalmente da concepção anterior - a notar pela marcante observação de que "o pacífico [colombiano] foi construído [...] como uma entidade 'developmentalizable" (Escobar, 2008, p. 159) - a reflexão sobre o desenvolvimento se alinha mais claramente à crítica da modernidade. Porém, aqui há uma ambiguidade. Enquanto a visão crítica da modernidade é almejada, ela não descarta certa afinidade com projetos menos radicais que ainda possam ser transformadores. Escobar passa a vislumbrar o diálogo construtivo com um tipo de perspectiva que ainda se alimenta das possibilidades de o desenvolvimento ser reconfigurado, que é o caso das propostas de Anthony Bebbington, Norman Long e Alberto Arce. Para estes autores, não apenas se transmutam as formas pelas quais o desenvolvimento é formulado e implementado 
nos lugares (a própria consideração com as formas locais de ação, de conhecimento e de revisão dos projetos é essencial), mas também a própria modernidade pode aparecer, pelo menos, em "modernidades" alternativas. Por outro lado, Escobar (Idem, pp. 176-196) percebe que, a partir de pesquisa empírica com povos indígenas e afrodescendentes na Colômbia, alternativas surgem de modo heterogêneo: algumas são apenas esquemas territorializados de desenvolvimento alternativo (baseados em segurança alimentar e bem-estar da população); outras ensejam uma postura de oposição aos modelos de intervenção, que Escobar denomina de modernidades alternativas; por fim, a radicalidade, de fato, existe em uma experiência analisada pelo autor, que ele equaliza como a busca por alternativas à modernidade. Essa seria a única a escapar das armadilhas do discurso que supõe não existir espaço fora da modernidade (e do discurso do desenvolvimento). Volto ao assunto adiante.

Como movimento que surgem no ambiente acadêmico após a onda de trabalhos identificados com o pós-desenvolvimento, um conjunto de autores moveu respostas contundentes. Se a contraposição à narrativa do desenvolvimento objetivou pontos nodais, tais como o discurso totalizante, o hiato que aumentou entre países centrais e periféricos durante o período desenvolvimentista, as consequências ao ambiente e o sistema de poder que inventou o terceiro mundo, a perspectiva do pós-desenvolvimento é acusada, por sua vez, de homogeneizar projetos e políticas de desenvolvimento, que, na prática, foram mais diversos e menos orquestrados do que se conclui (Storey, 2000; Ziai, 2007).

Grande inspiração dos autores do pós-desenvolvimento, a arqueologia foucaultiana propõe que discursos são fragmentados, interrompidos, possuem diferenças e descontinuidades. Essa premissa foi fracamente articulada em favor de apontar o sistema de poder da narrativa do desenvolvimento, entendida quase como monolítica e coesa (Ziai, 2007, pp. 112-114). Como efeito, Ziai observa que no pós-desenvolvimento dois vetores transparecem com fraqueza. No primeiro, a própria essencialização do desenvolvimento e, no segundo, sua interpretação, pelos seus expoentes, como algo que as pessoas querem, mas não sabem o que é. A crítica de Ziai é sutil, pois se intromete no segundo problema a categoria da falsa consciência, expurgada pelos pesquisadores que se desvencilhavam de dilemas teóricos advindos do marxismo.

A interpretação de Storey (2000) orienta-se para outra direção. Um dos pontos delicados nas propostas do pós-desenvolvimento reside na romantização e na confiança excessiva que os intelectuais depositaram em movimentos sociais, compreendidos como espaços em que relações efetivamente democráticas e antiautoritárias imperam. O problema, para Storey, é culpar Estados, organismos e agências de desenvolvimento, tendo como cenário de esperança a sociedade civil e os movimentos como libertadores da máquina autoritária.

Embora Storey e Ziai não sejam céticos e apontem a perspicácia de determinadas proposições dos autores vinculados ao pós-desenvolvimento, mencionam que o "desejo" das pessoas por melhorar a qualidade de vida (independentemente do que se entenda por isso) poucas vezes aparece como questão legítima. O pós-desenvolvimento não oferece soluções. Isso leva ao problema das capacidades de agência e de resistência nos locais em que projetos são conduzidos, dimensões pouco mencionadas. A avaliação de Pottier (2003) acerca disto é bastante segura: a crítica não percebe que qualquer projeto de desenvolvimento, na prática, é muito mais sujeito às demandas locais, mesmo que no discurso exista, de praxe, um tom monocórdio. Se o desenvolvimento ocorre num conjunto de relações complexas que são irremediavelmente situadas, portanto sujeitas à conjuntura e aos atores que conduzem os planos, qualquer projeto opera em ambiente de poder e, nesse, formas de negociação se fazem presentes.

Nas réplicas dos autores defensores de uma era livre do desenvolvimento planejado, nota-se que o pós-desenvolvimento não resistiu a algumas lúcidas respostas. Isso também aparece na antropologia aplicada, que, mesmo trabalhando a "favor do desenvolvimento" por décadas, tenta reconstituir seu papel recentemente para uma inserção mais analítica, direcionada à abordagem etnográfica dos projetos e reconhecendo o potencial de certa abertura ao pós-estruturalismo e ao pós-desenvolvimento (Mosse e Lewis, 2006). No entanto, o "diálogo" 
entre defensores e críticos do desenvolvimento acabou por esclarecer mal-entendidos e, por seu turno, criou novas diferenças e soluçōes. Primeiro, tanto para Rist como para Escobar, o que unifica a perspectiva não é o exame específico de atitudes tomadas ou programas particulares de desenvolvimento - como parece se aproximar o estudo de Ferguson (1990). Antes, a crítica se dirige à fé e à ideologia, "um modelo explanatório ou uma formação discursiva que forma certas práticas que tendem em direção a uma 'mercantilização universal' [...]" (Rist, 2008, p. 257). Segundo, se os autores não oferecem soluçôes, Rist insiste na atitude e sublinha que o ponto é justamente este: o desenvolvimento está na raiz dos problemas e não deve ser substituído por algum programa que clame por validade universal (2008, p. 258). Terceiro, ainda contrarresposta de Rist, embora o pós-desenvolvimento ter sido fulminado por alimentar uma visão romântica de povos tradicionais e movimentos sociais, o mais impressionante é ver os formuladores do desenvolvimento não tolerarem quando grupos e movimentos sociais se afastam dos pilares da modernidade.

Certa oscilação se faz evidente. O pós-desenvolvimento, parece-me, vê-se diante do fato de não dar expressão e voz às formas locais e múltiplas de apropriação, inovação e resistência. Ainda no seu livro mais conhecido, Escobar afirmava que o "impacto das representaçôes do desenvolvimento é profundo no nível local. Nesse nível, conceitos de desenvolvimento e modernidade são resistidos, hibridizados com formas locais, transformados" (1995, p. 51). Todavia, se o impacto é profundo e o ponto nodal dos autores é justamente por sua violência e eficácia (isto é, por construir coisas) -, como a resistência e a hibridização ocorrem? Esse é o interstício de negociação e poder que cobram Storey (2000), Mosse e Lewis (2006) e especialmente Pottier (2003).

No seu livro mais recente, Escobar (2008, p. 348) igualmente aceita algumas das críticas dirigidas aos trabalhos anteriores, todavia insiste que o conflito interpretativo entre os pesquisadores se ajusta às orientaçôes teóricas em questão. Em uma passagem, que em sua brevidade induz ao leitor que respostas e réplicas acerca do assunto atingiram certo esgotamento, indaga se estaria errada a ênfase pós-estruturalista no discurso monolítico do desenvolvimento. Decididamente, Escobar sugere que não, haja vista que para operar de modo eficaz e poderoso, o discurso/prática do desenvolvimento necessitou de grande coerência, mesmo na maior multiplicidade de situações e casos empíricos em que se atualizou.

\section{Pós-desenvolvimento e a modernidade/colonialidade}

$\mathrm{Na}$ medida em que o pensamento dos autores do pós-desenvolvimento se consolida, ainda que numa atitude entre se defender e aceitar argumentos contrapostos, uma promissora associação concretiza-se com a revisão crítico-propositiva não apenas da modernização via desenvolvimento, mas também da modernidade como tal. Na formulação do pós-desenvolvimento, mostrei que inicialmente o problema situava-se nos discursos e, em alguma medida, nas práticas equacionadas por Estados, seja por meio da ajuda internacional, seja por organizações multilaterais e ONGs. Parecia faltar, portanto, um ponto de vista que conseguisse ser enfático simultaneamente no sistema de poder que as prescrições de desenvolvimento efetivam e na constituição da modernidade nas margens da Europa, dando fecunda visibilidade à agência propositiva que povos e grupos sociais empreendem como projetos de vida coletiva (local e/ou em rede). É quando se acasalam os esforços obtidos do pensamento pós-estruturalista com a recepção parcial da reflexão de autores identificados com o pós-colonialismo (Frantz Fanon, Edward Said, Homi Bhabha) e com os estudos subalternos (Dipesh Chakrabarty, Ranajit Guha, Gayatri Spivak) para rever criticamente postulados da modernidade e equacioná-la com a colonialidade (Quijano, 2000; Mignolo, 2000).

Quando me refiro a uma influência parcial dos estudos pós-coloniais e subalternos, sublinho, a partir da leitura de Mignolo (2000), que estes enfrentam diretamente o colonialismo inglês e encontram no período a partir do século XVIII seu campo de batalha. Dimensão particular é advinda quando o olhar é sobre o colonialismo ibérico. Por essa razão, para expoentes deste pensamento como Aníbal Quijano, Walter Mignolo, Catherine 
Walsh, Arturo Escobar e outros, também é central observar que fontes de inspiração propriamente latino-americanas são essenciais na crítica da modernidade/colonialidade, como as obras de José Carlos Mariátegui, Darcy Ribeiro e Paulo Freire.

A associação entre o pós-desenvolvimento e a crítica da modernidade/colonialidade vem sendo formada nos últimos anos em grupos de pesquisa, encontros diversos e debatida em periódicos específicos, bem como a colaboração incessante entre pesquisadores de instituiçōes diferentes. ${ }^{6}$ Essa aproximação, obviamente, é observada numa parcela dos autores que sentem afinidades entre as duas formulaçōes, particularmente aqueles devotados a estudar a América Latina. Destaco, a seguir, somente três pontos de contato entre crítica da modernidade e do desenvolvimento, buscando os nomes principais e uma descrição sintética, porém não é objetivo analisar obras ou autores em separado ou fazer a exegese de cada conceito, tema que daria pelo menos outro artigo.

A primeira premissa basilar é a que associa modernidade e colonialidade (Quijano, 2000; Mignolo, 1995, 2000). Questão inspirada nos trabalhos de Wallerstein e de Quijano, Mignolo sustenta que uma face não pode ser entendida sem a outra; isto, basicamente, implode a autointerpretação de uma modernidade saída de matrizes tais como o a Reforma protestante, o Iluminismo e a Revolução Francesa. Aqui emerge a ideia de exterioridade da modernidade e da Europa: ambas adquirem outros sentidos vistas de seu exterior, portanto o moderno não pode ser explicado pelo desenvolvimento intra-europeu, ele relaciona o colonialismo como fundante (especialmente o liderado pelas nações ibéricas). Assim, conceitos como diferença colonial, colonialidade do poder/saber e ferida colonial associam o espetacular desenvolvimento do capitalismo à colonização das Américas (Quijano, 2000, 2005), somados ao fato uma construção da diferença como subalterna e hierarquizada, uma incessante produção da violência sobre formas de vida não-identificadas com a europeia (Mignolo, 2000, 2005).

Desse modo, o que importa ressaltar é que como resultado de séculos de colonialidade, observam os pesquisadores, as premissas que orien- taram políticas de desenvolvimento nasceram de um passado longínquo de diferença com violência, cujo horizonte jamais suspendeu a subalternidade da relação. Ademais, nas últimas décadas com o advento da globalização o discurso do desenvolvimento adquiriu um formato associado ao caráter mundializado das relaçôes de mercado e às formas neoliberais de governo, eventualmente com a substituição dos programas planejados e centralizados por intervençôes em forma de ajustes econômicos estruturais, conforme recente análise de Ferguson (2006) para a África. Assim, concede-se uma característica única ao discurso: de que, além de não haver espaço para propostas que fujam das tentativas de desenvolvimento, independentemente das cores em que se apresente, também não existiria uma exterioridade à modernidade (Escobar, 2008). Nesse caso, o que os autores identificados com a crítica da modernidade/colonialidade se encorajam em tornar visível é justamente o silêncio imposto às alternativas à modernidade e ao desenvolvimento que são efetuadas por movimentos sociais e comunidades resistentes.

No Brasil, este debate é razoavelmente conhecido, embora pouco associado à discussão do desenvolvimento. É o caso de Costa (2004), que repreende a sociologia reflexiva de Giddens e Beck, argumentando não conseguirem vencer o resíduo evolucionista da sociologia da modernização. $\mathrm{Na}$ suposição dos autores, não mais as estruturas sociais das sociedades "desenvolvidas" representam o ponto de chegada, mas a noção de subjetividade reflexiva, que se pretende universal. (Pelo menos do prisma do elogio ao empreendimento moderno, a posição de Habermas não seria tão distinta, concluindo que as margens da Europa vivem uma modernidade que necessita ser completada.)

Autores como Costa (2004, 2006), Carvalho (2001) e Maia (2009) concluem ser não apenas possível, mas desejável ler a realidade brasileira pelas lentes do pós-colonialismo e da proposta modernidade/colonialidade/descolonização. Entretanto, essas vozes ainda são raras no ambiente acadêmico brasileiro. Respeitando as interpretações diversas, outros pesquisadores preferem uma leitura menos desconstrutiva e sugerem uma modernidade de algum modo redentora, ainda que ambivalente, 
passível de uma reconstrução (Domingues, 2002, 2009); ou uma modernidade seletiva na qual se pode entendê-la por conquistas e carências (Souza, 2000). Árdua tarefa é questionar o eurocentrismo, pois o desafio decolonial é compreender o Brasil sem recorrer aos cânones do ocidentalismo, interrogando livremente a ontologia que cunhou conceitos tais como indivíduo, sociedade, esfera pública, igualdade e "conteúdo emancipatório da modernidade".

A segunda particularidade é o afastamento da discussão sobre a economia (como os debates em torno do que seria um "desenvolvimento econômico mais justo") e a aproximação ao problema dos dispositivos de poder que operam nos âmbitos culturais e gnoseológicos. É o que mostram Walsh (2005), Mignolo (2005) e Blaser (2009) sobre a necessidade, durante longo tempo, de subjugação dos sistemas de conhecimento não europeus para afirmar a modernidade - o que Carvalho (2001) chamou de a "voz calada do nativo". ${ }^{8}$ A ela se relaciona a geopolítica da epistemologia que, sinteticamente, Mignolo (2005, p. 44) define como a distribuição desigual de conhecimento, e a recente recuperação de toda a sorte de práticas, saberes, epistemologias e cosmologias indígenas sintetizada na noção de "insurgência epistêmica” (Walsh, 2005). Insurgência experimentada por grupos indígenas e afrodescendentes na Bolívia, no Equador e na Venezuela (Escobar, 2010), também presentes, com mais ou menos ressonâncias, no mundo indígena, rural e mesmo urbano do Brasil (cf. Carvalho, 2001). Na visão de Mignolo, movimentos sociais, escritores, ativistas forçam um redesenho do mapa do conhecimento, operando o que ele denomina "desligar-se" [delinking] (Mignolo, 2000), uma destituição do saber eurocentrado como o único legítimo e cuja missão é efetuar uma produção de conhecimento descolonizante. Se todo o conhecimento é localizado pela diferença colonial com a criação do subalterno e do inferiorizado, então uma geopolítica da epistemologia desmascararia essa condição.

O deslocamento, portanto, é pensar o problema do desenvolvimento como um processo que naturalizou a versão modernizante para a qual o saber científico constitui o eixo de conhecimento válido. Por essa razão, a crítica do desenvolvimento pode se efetivar na insurgência epistêmica, na valorização $\mathrm{da}$ ancestralidade, na performance das ontologias-outras que não a ocidental (Blaser, 2009; De la Cadena, 2010).

O terceiro e último ponto de contato que sublinho diz respeito à forma como o conceito de desenvolvimento pode ser transmutado quando apropriado e politicamente utilizado. Walsh (2010) refere-se ao fato de que na nova constituição equatoriana a noção de buén vivir aparece como primordial. Resultado de décadas de lutas sociais, sumak kawsay, buén vivir em quéchua, constitui-se o que o desenvolvimento deve(ria) ser (Walsh, 2010; Escobar, 2010). Na realidade, Walsh mostra que viver bem é antes de tudo um projeto coletivo, daí o direcionamento que transmuta os atuais esforços das organizações e agências internacionais em torno do desenvolvimento humano, ou das formas ainda insistentes na dimensão material do desenvolvimento pensado como expansão tecnológica, de capital e de infraestruturas. Coletivo por princípio, interroga igualmente os aparelhos que querem criar liberdades econômicas, capacidades, oportunidades individuais e acesso a mercados como é o enaltecido projeto (liberal?) de Amartya Sen (2000).

Modificar os sentidos do desenvolvimento para, no caso limite, anulá-lo. Quando os territórios, os projetos endógenos e, em suma, a vida e a unicidade da experiência das pessoas (Blaser, 2004) passam fulgurar como âncoras da desconstrução de narrativas sobre progresso e história linear, o potencial é uma reconfiguração político-epistêmica que sinalize a colonialidade vigorosa que permeia todo princípio de representar, prescrever em nome de um desenvolvimento universal.

\section{Considerações finais}

Um conjunto de questôes permanece em aberto nessa trajetória que procurei mostrar desde uma primeira antropologia de mãos dadas com o desenvolvimento, passando pela infusão das perspectivas pós-colonial e pós-estruturalista e que adquire um corpo de produção no pós-desenvolvimento e seu diálogo com o programa modernidade/colonialidade. 
Talvez a mais evidente seja a ambiguidade do que seria uma transformação do desenvolvimento como narrativa generalizante e associada à modernidade/colonialidade, e recentemente à globalização, para uma abertura em direção aos processos locais, diferenciados, heterogêneos e endógenos, quiçá autônomos, de desenvolvimento. Ora, a circularidade impede a superação que o pós-desenvolvimento imaginou ou a "era" desejada foi apenas um modo de reverter o processo para uma configuração lugarizada, não mais universal e sim pluriversal? Não permaneceria, nesse sentido, certa perspectiva progressista e sempre passível de cooptação (às vezes, indireta) por entidades com mais poder e articulação (Estados e organizações quaisquer) que, de modo populista, encetariam expressões como participação, igualdade de gênero, princípio de diferença e interculturalidade para fazer valer mas de lo mismo? É o que alerta Walsh (2010) para uma ambígua assimilação pelo Estado a respeito do buén vivir equatoriano e seu (ab)uso na constituição daquele país.

Um problema adicional diz respeito ao que se pode denominar de "desejo do desenvolvimento" (DeVries, 2007). Não serão tão poderosas a narrativa do desenvolvimento e suas promessas que as pessoas realmente o querem? Aqui teríamos que ceder o lugar que era cômodo ao pós-estruturalismo e a correlata visão de que o poder cria necessidades, para uma abertura ao desejo, à sedução (e à sedação), tal qual oferece DeVries num ensaio de orientação lacaniana-deleuziana sobre o desenvolvimento. "As pessoas, nos Andes, querem las obritas", diz DeVries (2007), polemizando diretamente com Escobar e Ferguson (insistência também de Sheperd, 2004). Esse desejo não é livre de construção e persuasão, no entanto parece ser pouco promissor responder aos interlocutores em pesquisa de campo que suas vontades são falsas. A possibilidade é relativa a um desejo basilar, independentemente de as máquinas-desejantes estarem no seio ou nas margens da modernidade. Nesse caso, o projeto descolonizante teria que se acomodar a uma versão que substitui a oposição em essência entre "Ocidente e o resto" para uma compreensão da multiplicidade diferenciada e da parcialidade constitutiva do projeto moderno, exatamente aquela que propóem
Arce e Long em que se "acelera a fragmentação e a dispersão da modernidade para uma constante proliferação de modernidades" (2000, p. 1).

Mesmo neste caso, o repensar da modernidade e seus exteriores, especialmente na forma das insurgências epistêmicas, é frutífero ao reconfigurar e impulsionar criativamente o conteúdo elaborado inicialmente pelos autores ligados ao pós-desenvolvimento, pois o que parece pouco provável de duvidar é a ruína do desenvolvimento na maneira como foi planejado, dirigido, implantado e reformulado ao longo de décadas. Cabe ressaltar, por conseguinte, essa complexidade e a reinterpretação na forma de alternativas à modernidade ou modernidades alternativas, ambas fornecendo expressão aos "seus outros". Creio estar claro que elas interrompem justamente as tentativas de reconstrução e finalização da odisseia incompleta da Modernidade, rota que se apresenta de modo pouco plausível.

Comecei pela discussão antropológica e o debate embrionário que essa disciplina auxiliou a alicerçar quanto aos programas e projetos de desenvolvimento de grande porte. As interpretaçôes recentes, por modalidades particulares e ênfases distintas, conjugam forças para recolocar outra antropologia na paisagem acadêmica, criando interaçôes e tensões com a tradicional antropologia aplicada. Debruçando-se sobre os processos, as apropriações locais e os ideários latentes do assim chamado desenvolvimento, ela própria não necessariamente se identifica com estes vetores nem destrói desejos manifestos em campo, fatores capazes de rever os pressupostos que forneceram chaves no tratamento do/a "outro/a" num determinado momento.

\section{Notas}

1 Para uma crítica branda a respeito, ver Apthorpe (1985).

2 Conforme o artigo seminal de Stavenhagen (1985). Para um estudo recente, ver Verdum (2006).

3 Lema que igualmente não pôde escapar de uma decepção por parte de alguns analistas. Rist (2008, p. 194) observa que o segundo termo (sustentável) serviu apenas para legitimar o primeiro, isto é, a perpetuação do desenvolvimento como gramática inquestionável. De outra parte, pesquisadores denunciam que 
a cruzada do desenvolvimento sustentável propiciou o surgimento da eco-governamentalidade (Ulloa, 2005; Agrawal, 2005).

4 Todas as citações de textos em língua inglesa foram traduzidas por mim.

5 O leitor poderá buscar referências adicionais em outros autores, tais como Serge Latouche, Wolfgang Sachs, Helen Norberg-Hodge, Ivan Illich, Vandana Shiva, Gustavo Esteva, Raimundo Panikkar, Ashis Nandy, Silvia Perez-Vitoria, entre outros. Para uma visão crítica dos programas de desenvolvimento como capitalocêntros, ver Gibson-Graham (2006).

6 Refiro-me ao Modernity/coloniality working group, centrado na colaboração entre pesquisadores da Duke University e a University North Carolina at Chapel Hill, especialmente nas pessoas de Walter Mignolo e Arturo Escobar. O grupo conta com contribuiçōes mais ou menos frequentes (diretas e indiretas) de Anibal Quijano, Catherine Walsh, Enrique Dussel, Mario Blaser, Marisol de la Cadena e outros, assim como ativistas e membros de movimentos sociais. Entre 2000 e 2003, a Universidade de Duke editou o periódico Nepantla: Views from the South, cuja discussão se dava em torno do pós-colonialismo, dos estudos subalternos e de descolonização. Encerrado o journal, o debate migrou para o espaço intitulado Worlds and Knowledges Otherwise.

7 Domingues $(2002,2009)$ é receptivo de algumas teses de Walter Mignolo, mas não aceita a proposição principal. Para ele, Mignolo desfavorece o diálogo entre grupos, criando fronteiras que não seriam muito diferentes da proposta por Huntington, porém, no caso de Mignolo, olhando de modo benevolente o "Outro”. A ambivalência da modernidade é o que permite Domingues pensar que ela gerou liberdades e simultaneamente outras formas de dominação, além de asseverar riscos, angústias. Ainda assim, o autor entende que a modernidade, mesmo na sua "terceira fase" em que a heterogeneidade é uma marca, propiciou positivamente o aparecimento da reflexividade, da universalidade, das identidades abertas, da complexidade.

8 Ver também a esse respeito a inteligente discussão de Ploeg (1993).

\section{BIBLIOGRAFIA}

ABRAMOVAY, Ricardo. (2003), O futuro das regiōes rurais. Porto Alegre, Editora da UFRGS.
AGRAWAL, Arun. (2005), Environmentality: technologies of government and the making of subjects. Durham/Londres, Duke University Press.

APTHORPE, Raymond. (1985), "Pleading and reading agricultural development policy: small farm, big state, and the 'case of Taiwan'", in R. Grillo e A. Rew (eds.), Social anthropology and development policy, Londres/Nova York, Tavistock, 1985, pp. 88-101.

ARCE, Alberto \& LONG, Norman. (2000), "Reconfiguring modernity and development from an anthropological perspective", in (eds.), Anthropology, development and modernities: exploring discourses, counter-discourses and violence, Londres/Nova York, Routledge, pp. 1-31.

ASAD, Talal. (1973), "Introduction", in (ed.), Anthropology \& the colonial encounter, Londres, Ithaca Press; Humanities Press, pp. 9-19.

BLASER, Mario. (2004), "Life projects: indigenous peoples' agency and development", in M. Blaser, H. Feit e H. G. Mcrae (eds.), In the way: indigenous peoples, life projects, and development, Ottawa, IDRC, pp. 26-44.

. (2009), "Political ontology: cultural studies without 'cultures'”. Cultural Studies, 23 (5): 873-896.

BRESSER-PEREIRA, Luis Carlos. (2006), "Estratégia nacional e desenvolvimento". Revista de Economia Política, 26 (2): 203-230.

CARVALHO, José Jorge. (2001), “O olhar etnográfico e a voz subalterna”. Horizontes Antropológicos, 15: 107-147.

COCHRANE, Glynn. (1971), Development anthropology. Nova York, Oxford University Press.

CORBRIDGE. Stuart. (1994), "Post-marxism and post-colonialism: the needs and rights of distant strangers", in D. Booth (ed.), Rethinking social development: theory, research and practice, Malaysia, Longman Scientific \& Techical, pp. 90-117.

COSTA, Sergio. (2004), "Quase crítica: insuficiências da sociologia da modernização reflexiva". Tempo Social, 16 (2): 73-100. 
(2006), "Desprovincializando a sociologia: a contribuição pós-colonial”. Revista Brasileira de Ciências Sociais, 21 (60): 117-183.

DAHL, Gudrun \& HJORT, Anders. (1984), "Development as message and meaning". Ethnos, 49 (3-4): 165-185.

De la CADENA, Marisol. (2010), "Indigenous cosmopolitics in the Andes: conceptual reflections beyond 'politics". Cultural Anthropology, 25 (2): 334-370.

DeVRIES, Peter. (2007), "Don't compromise your desire for development! A Lacanian/Deleuzian rethinking of the anti-politics machine". Third World Quarterly, 28 (1): 25-43.

DOMINGUES, José Maurício. (2002), Interpretando a modernidade: imaginário e instituiçôes. Rio de Janeiro, FGV.

. (2009), "Global modernization, 'colonization' and a critical sociology for contemporary Latin America”. Theory, Culture \& Society, 26 (1): 112-133.

ESCOBAR, Arturo. (1995), Encountering development: the making and unmaking of the Third World. Princeton, Princeton University Press.

. (2000), "El lugar de la naturaleza y la naturaleza del lugar: ¿globalización o postdesarrollo?", in E. Lander (org.), La colonialidad del saber: eurocentrismo y ciencias sociales. Perspectivas latinoamericanas. Buenos Aires, Flacso, pp. 113-143.

. (2008), Territories of difference: place, movements, life, redes. Durham, Duke University Press.

. (2010), "Latin America at crossroads: alternative modernizations, post-neoliberalism, or post-development”. Cultural Studies, 24 (1): $1-65$.

ESTEVA, Gustavo. (1992), "Development”, in W. Sachs (ed.), The development dictionary: a guide to knowledge as power, Londres, Zed Books, pp. 6-25.

FERGUSON, James (1990), The anti-politics machine: "development", depoliticization, and bureaucratic power in Lesotho. Cambridge/Nova York, Cambridge University Press.

(1999), Expectations of modernity: myths and meanings of urban life on the Zam- bian copperbelt. Berkeley/Los Angeles, University of California Press.

. (2006), Global shadows: Africa in the neoliberal world order. Durham, Duke University Press.

GARDNER, Katy \& LEWIS, David. (1996), Anthropology, development, and post-modern challenge. Londres/Chicago, Pluto Press.

GIBSON-GRAHAM, J. K. (2006), Postcapitalist politics. Minneapolis, University of Minnesota Press.

GRILLO, Ralph. (1985), "Applied anthropology in the 1980s: retrospect and prospect", in R. Grillo e A. Rew (eds.), Social anthropology and development policy, Londres/Nova York, Tavistock Publication, pp. 1-36.

HOBART, Mark. (1993), "Introduction: the growth of ignorance?", in (ed.), $A n$ anthropological critique of development: the growth of ignorance. Londres, Routledge, pp.1-30.

MAIA, João Marcelo. (2009), "Pensamento brasileiro e teoria social: notas para uma agenda de pesquisa”. Revista Brasileira de Ciências Sociais, 24 (71): 155-168.

MIGNOLO, Walter. (1995), The darker side of the Renaissance: literacy, territoriality, and colonization. Ann Arbor, University of Michigan Press. . (2000), Local histories/global designs: coloniality, subaltern knowledges, and border thinking. Princeton, Princeton University Press. . (2005), The idea of Latin America. Malden/Oxford, Blackwell.

MOSSE, David \& LEWIS, David. (2006), “Theoretical approaches to brokerage and translation in development", in D. Lewis e D. Mosse (eds.), Development brokers and translators: the ethnography of aid and agencies, Bloomfield, Kumarian Press, pp. 1-26.

PLOEG, Jan Dowue van der. (1993), "Potatoes and knowledge", in M. Hobart (ed.), An anthropological critique of development: the growth of ignorance, Londres, Routledge, pp. 209-227. POTTIER, Johan. (2003), "Negotiating local knowledge: an introduction", in J. Pottier, A. Bicker e P. Sillitoe (eds.), Negotiating local knowledge: power and identity in development, Londres, Pluto Press, pp. 1-29. 
QUIJANO, Aníbal. (2000), "Coloniality of power, eurocentrism, and Latin America". Nepantla: Views from the South, 1 (3): 533-580. . (2005), "Dom Quixote e os moinhos de vento na América Latina". Estudos Avançados, 19 (55): 9-31.

RAHNEMA, Majid \& BAWTREE, Victoria (eds.). (1997), The post-development reader. Londres, Atlantic Highlands.

RIBEIRO, Gustavo Lins. (2005), "Poder, redes e ideologia no campo do desenvolvimento". Série Antropologia, 383: 1-19.

RIST, Gilbert. (2008), The history of development: from western origins to global faith. 3 ed., Londres, Zed books.

SACHS, Wofgang (ed.). (1992), The development dictionary: a guide to knowledge as power. Londres, Atlantic Highlands/Zed Books.

SAID, Edward. (1978), Orientalism. Nova York, Vintage Books.

SCHNEIDER, Sergio. (2004), "A abordagem territorial do desenvolvimento rural e suas articulaçôes externas”. Sociologias, Porto Alegre, 11: 88-125.

SCHRÖDER, Peter. (1997), "A antropologia do desenvolvimento: é possível falar de uma subdisciplina verdadeira?". Revista de Antropologia, 40 (2): 83-100.

SEN, Amartya Kumar (2000), Desenvolvimento como liberdade. São Paulo, Companhia das Letras.

SHEPERD. Chris. (2004), "Agricultural hybridity and the "pathology" of traditional ways: the translation of desire and need in postcolonial development". Journal of Latin American Anthropology, 9 (2): 235-266.

SOUZA, Jessé. (2000), A modernização seletiva: uma reinterpretação do dilema brasileiro. Brasília, Editora da UnB.

STAVENHAGEN, Rodolfo. (1985), "Etnodesenvolvimento: uma dimensão ignorada no pensamento desenvolvimentista”. Anuário Antropológico, 84: 11-44.

STOREY, Andy. (2000), "Post-development theory: romanticism and Pontius Pilate politics". Development, 43 (4): 40-46.

ULLOA, Astrid. (2005), The ecological native: indigenous peoples' movement and the eco-gover- nmentality in Colombia. Nova York/Londres, Routledge.

VEIGA, José Eli. (2006), Desenvolvimento sustentável: o desafio para o século XXI. 2 ed. Rio de Janeiro, Garamond.

VERDUM, Ricardo. (2006), Etnodesenvolvimento: novalvelha utopia do indigenismo. Brasília, tese de doutorado, UnB.

WALSH, Catherine (org.). (2005), Pensamiento critico y matriz (de)colonial: reflexiones latinoamericanas. Quito, Abya-Yala.

. (2010), "Development as buen vivir: institutional arrangements and (de)colonial entanglements". Development, 53 (1): 15-21.

ZIAI, Aram. (2007), “The ambivalence of post-development: between reactionary populism and radical democracy", in (ed.), Exploring post-development: theory and practice, problems and perspectives, Londres, Routledge, pp. 111-128. 


\section{DESENVOLVIMENTO, PÓS- ESTRUTURALISMO E PÓS- DESENVOLVIMENTO: A CRÍTICA DA MODERNIDADE E A EMERGÊNCIA DE "MODERNIDADES" ALTERNATIVAS}

\section{Guilherme Francisco Waterloo Radomsky}

Palavras-chave: Desenvolvimento; Pós-desenvolvimento; Alternativas à modernidade; Descolonização; Antropologia aplicada.

Com uma história de mais de meio século de políticas, programas e debates teóricos, o tema do desenvolvimento sustenta-se incansável nas ciências sociais. Concedendo especial atenção à produção antropológica sobre o assunto, este artigo analisa parte do percurso que leva a antropologia do desenvolvimento às críticas pós-estruturalista e pós-colonial sobre o tema e a concretização da perspectiva multidisciplinar denominada de pós-desenvolvimento. Após um balanço em torno da proposta do pós-desenvolvimento, volta-se para a recente aproximação desta com a crítica da modernidade por meio da noção de descolonização. Ao final, examinam-se quais expectativas aparecem no diálogo entre interpretaçōes acerca de um tema que se reinventa e se reconfigura em possibilidades teóricas múltiplas.

\section{DEVELOPMENT, POST- \\ STRUCTURALISM, AND \\ POST-DEVELOPMENT: \\ CONTROVERSIES BETWEEN \\ (THE CRITIQUE OF) MODERNITY \\ AND THE EMERGENCE OF ALTERNATIVE "MODERNITIES"}

\section{Guilherme Francisco Waterloo \\ Radomsky}

Keywords: Development; Post-development; Alternatives to modernity; Decolonization; Applied anthropology.

Over a period of more than fifty years of policies, programs, and theoretical debates, the theme of development remains persuasive in social sciences. Giving special attention to the anthropological reflection over this topic, this article analyzes the path from the beginning of the development anthropology to the post-structuralist and post-colonial critique as well as the emergence of a multidisciplinary perspective known as post-development. Following the discussion over ideas of post-development, we turn our focus to the recent association between this perspective and the critique of modernity through the notion of decolonization. Moreover, we examine which problems come up in the dialogue among interpretations over an issue that can reinvent and reconfigure itself in multiple theoretical possibilities.

\section{DÉVELOPPEMENT, POST- STRUCTURALISME ET POST-DÉVELOPPEMENT: LA CRITIQUE DE LA MODERNITÉ ET L'ÉMERGENCE DE "MODERNITÉS" ALTERNATIVES}

\section{Guilherme Francisco Waterloo Radomsky}

Mots-clés: Développement; Post-développement; Alternatives à la modernité; Décolonisation; Anthropologie appliquée.

Malgré une histoire de politiques, de projets et de débats théoriques de plus d'un demi-siècle, le thème du développement se maintient toujours au centre des sciences sociales. En accordant une attention spéciale à la production anthropologique sur ce sujet, l'article analyse une partie de la trajectoire qui conduit l'anthropologie du développement vers des critiques post-structuralistes et postcoloniales, et vers l'affirmation d'une perspective pluridisciplinaire qui s'est définie à propos de la notion de post-dévéloppement. Après une appréciation de la proposition du post-développement, l'article analyse son rapprochement croissant avec la critique de la modernité à travers la notion de décolonisation. En conclusion, sont examinées les attentes qui se posent dans le dialogue autour des interprétations sur un sujet qui se réinvente et se rétablit en nombreuses possibilités théoriques. 